\title{
PROJETOS DE TI NO CONTEXTO UNIVERSIDADE-EMPRESA: UM DIAGNÓSTICO DAS PARTICULARIDADES E CONTINGÊNCIAS QUE DESAFIAM A GESTÃO DE PROJETOS
}

Luiza Curto Camarano (luizaccamarano@gmail.com) - Universidade Federal de Minas Gerais.

Marina Teixeira Vidigal (matvidigal@gmail.com) - Universidade Federal de Minas Gerais.

Raoni Barros Bagno (rbagno@dep.ufmg.br) - Universidade Federal de Minas Gerais

\section{RESUMO}

O crescente envolvimento das universidades com projetos de pesquisa e extensão em parceria com as empresas tem anunciado novos desafios a gestão de projetos (GP). A literatura oferece algumas possiveis abordagens a estes desafios, com destaque para a chamada GP Tradicional e os Métodos Ágeis. Contudo, o ambiente das universidades apresenta uma série de particularidades. Em especial no caso de projetos de Tecnologia da Informação (TI), seu crescente protagonismo econômico e social representa um recorte ainda mais importante. Este estudo diagnostica particularidades de projetos de TI realizados por universidades em parceria com empresas a fim de fomentar abordagens de gestão mais adequadas. Para isso, foi realizado um estudo retrospectivo em dois projetos conduzidos no contexto de um laboratório da UFMG por meio de entrevistas semiestruturadas com membros das equipes e análise documental. Ao final, considerações da literatura são confrontadas com o contexto de campo, extraindo-se implicações e recomendações para a GP neste contexto, a fim de extrair melhores resultados da relação universidade-empresa.

\section{Palavras chave: Gestão de projetos. Gestão Ágil. Tecnologia da Informação. Relação Universidade-Empresa.}

\section{INTRODUÇÃO}

A Gestão de Projetos (GP) vem ganhando importância nas organizações modernas. Nas décadas de 60 e 70 as abordagens de GP incorporavam majoritariamente áreas de engenharia de projeto e construção (CODAS, 1987), contudo, atualmente englobam conhecimentos diversificados como os de relações humanas, finanças, economia e engenharia de sistemas. $\mathrm{O}$ Instituto de Gerenciamento de Projetos (PMI), uma das maiores associações do mundo voltadas para este segmento, oferece cerca de oito tipos de certificações e conta com mais de 700.000 membros certificados em todo o mundo (PMI, 2016). Deve-se destacar, no entanto, sua abordagem normativa e prescritiva (MARQUES; PLONSKI, 2011) embasada por modelos fixos e previsíveis (SHENHAR; DVIR, 2007), compilados em um conjunto de práticas e técnicas para a GP que, juntos, compõem a chamada teoria Tradicional de Gestão de Projetos (EDER et al., 2015).

Uma alternativa a essa estrutura seria adaptar o projeto ao ambiente, à tarefa e à meta e não se ater a um conjunto de regras (SHENHAR; DVIR, 2007). Dessa forma, nos últimos anos, 
estudos como os de Shenhar e Dvir (2007) e de Silva e Amaral (2014), tem questionado a capacidade da teoria Tradicional de atender demandas de ambientes dinâmicos, com elevado grau de incerteza e mudanças constantes. Muitos desses ambientes relacionam-se aos projetos de inovação e a corrente de empreendedorismo que se faz presente no contexto atual.

Nesse sentido, as universidades brasileiras também tem se envolvido de maneira crescente com situações que demandam uma GP eficaz, devido às parcerias universidade-empresa e aos crescentes investimentos do governo em projetos de inovação tecnológica. Dentre os projetos desenvolvidos nas universidades, destacam-se os da área de Tecnologia da Informação (TI), que são tipicamente dinâmicos, com alto grau de incertezas, e lidam com renovação constante das plataformas de produtos e com a necessidade da gestão do conhecimento aplicada (LOPES; MAÑAS, 2013). Com a ascensão da indústria de TI ao longo dos anos, surgiram paralelamente instituições voltadas para o fomento de projetos da área, principalmente em parceria com universidades (SOFTEX, 2016). Neste contexto, emerge uma lacuna no que tange a compreensão da natureza (desafios, contingências, etc.) destes projetos, fazendo com que abordagens consolidadas de GP potencialmente não se adequem às demandas de projetos de TI no contexto acadêmico.

O objetivo deste trabalho é diagnosticar as contingências de projetos de TI em universidades a fim de fomentar abordagens mais adequadas para esta categoria de projetos. Em particular, o estudo investiga dois projetos executados por um laboratório da UFMG que foram realizados em parceria com empresas de diferentes segmentos, extraindo a partir dessas experiências desafios típicos de GP endereçáveis a distintas dimensões das abordagens tradicional e ágil.

\section{REVISÃO BIBLIOGRÁFICA}

O PMI e outros institutos da área de GP trabalham tipicamente com a difusão da informação por meio de "guias de conhecimento": textos normativos que servem como padrão de terminologia e que se aplicam a uma grande parte dos projetos (EDER et al., 2012). O mais difundido entre eles é o PMBOK (Project Management Body of Knowledge), que está em sua quinta edição (PMI, 2013) e que se tornou o padrão da disciplina (SHENHAR; DVIR, 2007). O PMBOK é bem aceito por grande parte das empresas que o empregam como o manual para gestão de seus projetos (SHI, 2011). O conjunto de guias é rotulado, atualmente, como a "teoria Tradicional" devido ao surgimento de outras abordagens que propõem princípios, ações, técnicas e ferramentas distintas para a GP. Segundo o PMI, o gerenciamento de um projeto normalmente inclui, mas não se limita a:

- Identificação dos requisitos;

- Abordagem das diferentes necessidades, preocupações e expectativas das partes interessadas no planejamento e execução do projeto;

- Estabelecimento, manutenção e execução de comunicações ativas, eficazes e colaborativas entre as pastes interessadas;

- Gerenciamento das partes interessadas visando o atendimento aos requisitos do projeto e criação das suas entregas;

- Equilíbrio de restrições conflitantes do projeto que incluem, mas não se limitam a (i) Escopo, (ii) Qualidade, (iii) Cronograma, (iv) Orçamento, (v) Recursos, e (vi) Riscos.

Shenhar e Dvir (2007) declaram que o fracasso de muitos projetos está relacionado a problemas que se originam da estrutura e da mentalidade que impulsionam a abordagem Tradicional. Por isso, nos últimos anos, tal literatura tem sido alvo de críticas relacionadas ao 
uso generalizado das práticas e às limitações da teoria quando utilizadas em ambientes dinâmicos de negócio, com altos níveis de incertezas e mudanças constantes. Este seria o cenário típico dos projetos de inovação (EDER et al, 2012).

Neste contexto, os métodos Ágeis vêm ganhando cada vez mais visibilidade, ao ponto de serem considerados uma das abordagens centrais de GP (ŠPUNDAK, 2014). Segundo Hodas et al. (2005) são evidentes a crescente aplicação da metodologia Ágil nos projetos modernos evidenciadas pelas inúmeras pesquisas conduzidas na área - e o valor que a indústria percebe neste tipo de abordagem.

As práticas ágeis confrontam paradigmas do método Tradicional por surgirem de uma necessidade de gerenciar projetos de alto índice de incertezas e complexidade, com metas e soluções indeterminadas e alta volatilidade e adaptabilidade (FERNANDEZ; FERNANDEZ, 2009). Eder et al. (2015) citam importantes características da GP Ágil: (i) o plano do projeto é realizado sucessivas vezes e com menos detalhes por vez, buscando as entregas mais importantes; (ii) o plano é detalhado em horizonte curto de tempo; (iii) o escopo é focado na visão do produto, contendo uma descrição abrangente e orientada para a resolução de problemas; (iv) controle do escopo é realizado por meio de priorizações apontadas pelo cliente; (v) baixo nível de formalidade; (vi) reuniões diárias curtas; e (vii) participação do cliente em todas as etapas.

Highsmith (2012) aponta um modelo para aplicação de práticas ágeis em GP de novos produtos composto por cinco fases: Visão, Especulação, Exploração, Adaptação e Encerramento. Já Hodas et al. (2005) apontam diferentes propostas de métodos ágeis: Crystal, Feature Driven Development (FDD), Dynamic Systems Development Method (DSDM), Adaptive Software Development, Scrum e XP, sendo as duas últimas as mais popularmente utilizadas.

De modo a sintetizar os conhecimentos das abordagens de GP, o Quadro 1 foi construído. Ele é formado por uma síntese bibliográfica referente a GP. Nas colunas tem-se os tipos Tradicional e Ágil, enquanto nas linhas são contemplados parâmetros de análise, como, a evolução do projeto, gestão dos recursos, definição do escopo. Com base neste quadro, foram traçados critérios para a realização do Estudo de Caso.

\section{METODOLOGIA DE PESQUISA}

Realizou-se um estudo de caso retrospectivo em dois projetos que atendiam os seguintes requisitos: terem sido desenvolvidos em parceria com empresas de diferentes segmentos; provirem de um contrato formal com a universidade, respeitando as burocracias do processo; finalizados há menos de um ano, de modo a facilitar o acesso à documentação e aos envolvidos; e ter tido uma extensão mínima de um ano, uma vez que a complexidade do projeto está diretamente ligada a necessidade de uma gestão mais eficaz. Por questões de confidencialidade, o nome do laboratório, dos projetos e das empresas serão omitidos. A figura 1 sintetiza os passos tomados para elaboração do estudo. 
Quadro 1 - Síntese da Revisão Bibliográfica

\begin{tabular}{|c|c|c|}
\hline & Tradicional & Ágil \\
\hline Plano de Projeto: & $\begin{array}{c}\text { Énfase no planejamento } \\
\text { detalhado e completo realizado } \\
\text { previamente à execução. }\end{array}$ & $\begin{array}{c}\text { Realizado sucessivas vezes, cada } \\
\text { vez com um grau de detalhe maior } \\
\text { das etapas que se aproximam. }\end{array}$ \\
\hline $\begin{array}{l}\text { Definição do } \\
\text { escopo: }\end{array}$ & $\begin{array}{l}\text { Primeira etapa do projeto, } \\
\text { aborda a solução da maneira } \\
\text { mais precisa possível. }\end{array}$ & $\begin{array}{c}\text { É focada na visão do produto, } \\
\text { contendo uma descrição abrangente } \\
\text { e orientada para a resolução de } \\
\text { problemas. }\end{array}$ \\
\hline $\begin{array}{l}\text { Gestão dos } \\
\text { recursos: }\end{array}$ & $\begin{array}{c}\text { Recursos são alocados } \\
\text { inicialmente no Plano de Projeto } \\
\text { e acompanhados com } \\
\text { indicadores. }\end{array}$ & $\begin{array}{l}\text { Realizada durante os sucessivos } \\
\text { planos e cotada em um curto } \\
\text { período de tempo. }\end{array}$ \\
\hline $\begin{array}{l}\text { Funções do } \\
\text { coordenador: }\end{array}$ & $\begin{array}{c}\text { Responsável pela criação do } \\
\text { Plano de Projeto e por todas } \\
\text { etapas subsequentes. }\end{array}$ & $\begin{array}{l}\text { Responsável pelo projeto porém } \\
\text { conta com a participação efetiva de } \\
\text { toda equipe de projeto. }\end{array}$ \\
\hline $\begin{array}{l}\text { Localização da } \\
\text { equipe de projeto: }\end{array}$ & $\begin{array}{c}\text { Varia de acordo com as } \\
\text { particularidades do projeto: } \\
\text { Equipes virtuais ou equipes } \\
\text { colocalizadas, dependendo das } \\
\text { atividades. }\end{array}$ & $\begin{array}{c}\text { Membros colocalizados, para que a } \\
\text { autogestão seja realizada de } \\
\text { maneira positiva. }\end{array}$ \\
\hline $\begin{array}{l}\text { Equipes de } \\
\text { projeto: }\end{array}$ & $\begin{array}{c}\text { A equipe do projeto inclui o } \\
\text { gerente do projeto, o pessoal de } \\
\text { gerenciamento do projeto e } \\
\text { outros membros da equipe que } \\
\text { executam o trabalho. }\end{array}$ & $\begin{array}{l}\text { Preferencialmente equipes } \\
\text { pequenas com comunicação rápida } \\
\text { e efetiva. }\end{array}$ \\
\hline $\begin{array}{l}\text { Monitoramento da } \\
\text { evolução do } \\
\text { projeto: }\end{array}$ & $\begin{array}{l}\text { Atividades organizadas de forma } \\
\text { hierárquica e sequenciada. }\end{array}$ & $\begin{array}{l}\text { Reuniões diárias curtas e } \\
\text { detalhamento de atividades em } \\
\text { horizonte curto de tempo. }\end{array}$ \\
\hline $\begin{array}{l}\text { Acompanhamento } \\
\text { do projeto: }\end{array}$ & $\begin{array}{l}\text { Relatórios de acompanhamento } \\
\text { frequentes; Progresso é } \\
\text { avaliado por indicadores. }\end{array}$ & $\begin{array}{c}\text { Realizada por meio de priorizações } \\
\text { apontadas pelo cliente. O progresso } \\
\text { é feito a partir de resultados } \\
\text { tangíveis e orientado pela } \\
\text { frequência de feedbacks. } \\
\end{array}$ \\
\hline $\begin{array}{l}\text { Participação do } \\
\text { Cliente: }\end{array}$ & $\begin{array}{l}\text { Em geral, assume papel } \\
\text { passivo, sendo comunicado do } \\
\text { andamento pelo gerente de } \\
\text { projeto. }\end{array}$ & Participação em todas as etapas. \\
\hline
\end{tabular}

\section{Fonte: dos autores}

Entrevistas semiestruturadas foram então aplicadas junto a participantes dos projetos. Foram entrevistados pelo menos um professor, um graduado, mestrando ou doutorando e um aluno de graduação. Todas elas foram individuais e presenciais e o roteiro foi delineado com base nos parâmetros da GP identificados na revisão bibliográfica, além de contarem com uma narrativa geral do projeto por parte de cada entrevistado. Também foram tomados alguns dados secundários dos projetos como: (i) cronogramas, (ii) listas de entregáveis, (iii) atas de reunião, (iv) proposta técnica e escopo do projeto. Estes foram analisados de modo a confrontar possíveis inconsistências e esclarecer dúvidas das entrevistas.

A partir das entrevistas, foi possível gerar dados que relacionados a alguns dos desafios centrais dos projetos do laboratório. Ao procurar padrões nas falas dos entrevistados de um mesmo projeto, foi possível reconstruir as histórias de forma semelhante ao real e ao procurar convergências entre os projetos foi possível identificar traços de comportamento. Nos dois momentos, a construção do cenário foi baseada também em uma comparação com o 
framework construído na fase de pesquisa teórica, buscando possível direcionamento para alguma abordagem de gerenciamento.

Figura 1. Síntese da metodologia do estudo

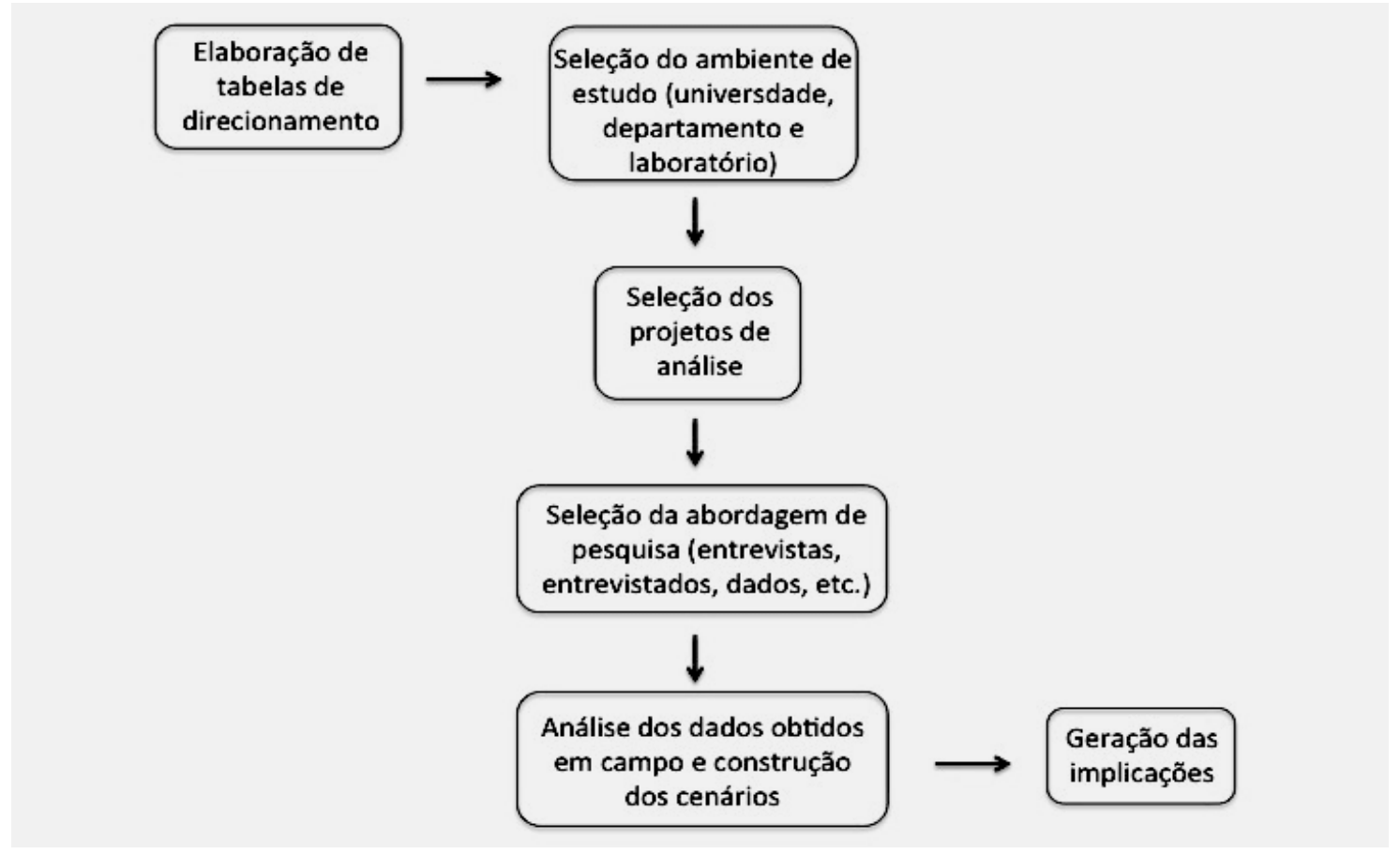

Fonte: dos autores

\section{O ESTUDO DE CASO}

A partir dos critérios determinados na Metodologia foi definido, que um laboratório da Universidade Federal de Minas Gerais (UFMG) seria o alvo da pesquisa de campo. O quadro 2 traz uma síntese dos principais aspectos associados a condução destes projetos à luz dos parâmetros identificados na revisão teórica.

O projeto A foi executado entre 2015 e 2016, com duração prevista de um ano e teve como objetivo obter um software de reconhecimento e monitoramento sensorial a fim de prevenir acidentes domésticos. Iniciou-se com a abertura de um edital de Pesquisa e Desenvolvimento (P\&D) da empresa Alfa - empresa de capital aberto, no ramo de Tecnologia de Informação e Comunicação - que tinha interesse nas áreas de atuação dos laboratório. Logo o professor gerente do projeto, elaborou uma proposta técnico-comercial que se adequava as áreas estabelecidas e assim, foi um dos selecionados. Para acompanhar o andamento do projeto eram realizadas reuniões semanalmente com toda a equipe. $\mathrm{Na}$ fase inicial, o interno era criado através de uma plataforma na internet denominada Trello, que norteava os alunos a respeito do que deveriam fazer durante a semana, e o oficial era apresentado a empresa Alfa pelo gestor do projeto. No fim de 2016 a empresa informou que projeto havia sido cancelado. Para a equipe, ficou claro que as partes não alinharam as expectativas em relação ao projeto o que culminou no fim antecipado. 
Quadro 2. Relação do estudo de campo com abordagens de GP.

\begin{tabular}{|c|c|c|}
\hline & Projeto A & Projeto B \\
\hline Plano de Projeto: & $\begin{array}{c}\text { Realizado no início do Projeto } \\
\text { contemplando escopo, orçamento } \\
\text { e questões contratuais. }\end{array}$ & $\begin{array}{c}\text { Realizado no início do Projeto } \\
\text { contemplando escopo, orçamento e } \\
\text { questões contratuais. }\end{array}$ \\
\hline $\begin{array}{l}\text { Definição do } \\
\text { escopo: }\end{array}$ & $\begin{array}{l}\text { Foi definido pelos professores em } \\
\text { conjunto com a Empresa Alfa. }\end{array}$ & $\begin{array}{l}\text { Foi definido pelos professores em } \\
\text { conjunto com a Empresa Beta. }\end{array}$ \\
\hline $\begin{array}{l}\text { Gestão dos } \\
\text { recursos: }\end{array}$ & $\begin{array}{c}\text { Recursos são determinados no } \\
\text { Plano de Projeto, parcelas são } \\
\text { pagas em certos períodos. Quem } \\
\text { realiza a gestão é a FUNDEP, } \\
\text { órgão da UFMG. }\end{array}$ & $\begin{array}{c}\text { Recursos são determinados no } \\
\text { Plano de Projeto, parcelas são pagas } \\
\text { em certos períodos. Quem realiza a } \\
\text { gestão é a FUNDEP, órgão da } \\
\text { UFMG. }\end{array}$ \\
\hline $\begin{array}{l}\text { Funções do } \\
\text { coordenador: }\end{array}$ & $\begin{array}{c}\text { Responsável pelo contato com a } \\
\text { empresa. }\end{array}$ & $\begin{array}{l}\text { Responsável pelo contato com a } \\
\text { empresa e pelas outras equipes } \\
\text { (Hardware e Empresa Gama) }\end{array}$ \\
\hline $\begin{array}{l}\text { Localização da } \\
\text { equipe de projeto: }\end{array}$ & $\begin{array}{c}\text { Equipe colocalizada no } \\
\text { laboratório, trabalhando junto } \\
\text { diariamente. }\end{array}$ & $\begin{array}{l}\text { Equipe de desenvolvimento de } \\
\text { Software colocalizada no laboratório, } \\
\text { trabalhando junto diariamente. }\end{array}$ \\
\hline Equipes de projeto: & $\begin{array}{l}\text { Equipe com competências } \\
\text { similares, pequenas. }\end{array}$ & $\begin{array}{l}\text { Equipe com competências similares, } \\
\text { pequenas. Sofreu muitas alterações. }\end{array}$ \\
\hline $\begin{array}{l}\text { Monitoramento da } \\
\text { evolução do } \\
\text { projeto: }\end{array}$ & $\begin{array}{c}\text { Reuniões semanais da equipe } \\
\text { toda e reuniões diárias da equipe } \\
\text { de desenvolvimento no início do } \\
\text { projeto. }\end{array}$ & $\begin{array}{c}\text { Reuniões mensais para discussão do } \\
\text { Projeto. }\end{array}$ \\
\hline $\begin{array}{l}\text { Acompanhamento } \\
\text { do projeto: }\end{array}$ & $\begin{array}{l}\text { Acompanhamento feito através de } \\
\text { relatórios semanais e mensais. }\end{array}$ & Acompanhamento trimestral \\
\hline $\begin{array}{l}\text { Participação do } \\
\text { Cliente: }\end{array}$ & $\begin{array}{l}\text { Assumiu papel ativo a partir da } \\
\text { metade do projeto. }\end{array}$ & $\begin{array}{l}\text { Contatos mais pontuais, em } \\
\text { entregas-chave do projeto. }\end{array}$ \\
\hline
\end{tabular}

Fonte: dos autores

O projeto $B$, surgiu por iniciativa da empresa Beta, estatal, de capital aberto, da área de energia. A ideia da empresa era desenvolver pesquisas em parceria com Universidades e convidar uma segunda empresa (empresa Gama) para que, por meio da transferência de tecnologia, produzisse o produto para o mercado e fornecesse diretamente para a empresa Beta. O objetivo do projeto era desenvolver um sistema de monitoramento aéreo de dutos no oceano. Para isso, a empresa Beta procurou o laboratório devido ao vasto conhecimento na área e juntos delimitaram escopo, orçamento, cronograma, entregáveis. Todos os itens do projeto foram formalizados pelo laboratório por meio de uma proposta técnica e posteriormente um contrato. Um dos professores realizava a função de gerente do projeto e assim, era responsável por representar a universidade frente à empresa Beta. Este projeto em especial, sofreu alterações sucessivas de equipe, devido à longa duração que acompanhou a evolução dos alunos na universidade (alguns formaram ou avançaram no curso e precisaram se desligar do laboratório). Os entrevistados destacaram a importância do trabalho ser desenvolvido em conjunto em um mesmo local físico pois auxiliava na transferência de conhecimento entre membros da equipe. A ideia inicial era que o projeto tivesse duração de dois anos, porém devido a postergações de verba estendeu-se por mais um ano. $\mathrm{O}$ escopo, em sua maioria, se manteve por todo o projeto. O orçamento e o processo de compras foram 
gerenciados pela Fundação local e coordenados pelo professor líder do projeto. Ao fim do projeto, foi realizada uma reunião de fechamento entre empresa Beta e o laboratório, na qual, segundo os entrevistados, a empresa se mostrou satisfeita com os resultados obtidos.

\section{RESULTADOS E DISCUSSÕES}

Inicialmente, é necessário abordar um ponto antagônico que o cenário de campo apresenta. De um lado estão as práticas gerenciais da universidade e das empresas. O primeiro exige com certa rigidez que pontos como definições de responsabilidade dos professores e as questões de propriedade intelectual sejam prontamente definidos no início para que o projeto seja liberado. O segundo exige que objetivo, cronograma, recursos sejam prontamente discutidos e decididos por completo antes do fechamento do contrato. De outro lado, a pouca previsibilidade dos projetos de pesquisa e inovação, que implica em maiores incertezas. Estas questões foram centrais para a análise que se segue.

O Plano de Projeto é um destes itens que deverá ser solucionado pensando em um sistema que respeite a natureza dos projetos. É preciso mesclar elementos das duas abordagens, Tradicional e da Ágil, de modo que o nível de informação originada no início do projeto permita a liberação do contrato e que também, dê flexibilidade para atuação dos gestores ao longo de todo projeto. O mesmo acontece com a Gestão do Recursos na qual um orçamento deverá ser estabelecido a fim de permitir a liberação de verba por parte da empresa e outros trâmites burocráticos, mas também deverá permitir alterações que acompanhem o escopo e as atividades do projeto, que por sua vez estão relacionados à imprevisibilidade.

Em relação à Definição do Escopo, a Gestão Ágil parece se enquadrar melhor no contexto observado. Para atender demandas de alteração, deverá haver foco na visão do produto, contendo uma descrição abrangente e orientada para a resolução de problemas. Para as Equipes de Projeto foram identificados na prática elementos da Gestão Ágil e recomenda-se que isso seja sistematizado com intencionalidade. Mudanças sucessivas de escopo se tornam mais difíceis com equipes grandes. Portanto, preferencialmente utilizam-se equipes pequenas cuja comunicação é rápida e efetiva. Em relação à localização da equipe, membros colocalizados, na qual a autogestão seja realizada de maneira efetiva, se torna fundamental em um cenário onde os alunos são os principais desenvolvedores. $\mathrm{O}$ fato da equipe possuir similaridades na natureza de suas competências corrobora com a estratégia de mantê-los em um mesmo ambiente de desenvolvimento.

O monitoramento da evolução do projeto também pode ser associado mais intimamente à Gestão Ágil. A abordagem Tradicional sugere que o monitoramento seja feito pelo controle das atividades organizadas de forma hierárquica, entretanto essa visão vai contra a natureza dos projetos de pesquisa principalmente no contexto do laboratório que necessita muitas vezes de melhorar a confiabilidade do software. Portanto indica-se realizar reuniões diárias curtas e detalhamento de atividades em horizonte curto de tempo. $O$ mesmo vale para o acompanhamento do projeto deve ser feito a partir de resultados tangíveis e orientado pela frequência de feedbacks. 
Quadro 3. Relação do estudo de campo com abordagens de GP

\begin{tabular}{|c|c|c|c|}
\hline & Recomendação & Justificativa & $\frac{\text { Particularidades }}{\text { do contexto }}$ \\
\hline Plano de Projeto: & $\begin{array}{c}\text { Abordagem híbrida que } \\
\text { respeite a natureza do } \\
\text { projeto }\end{array}$ & $\begin{array}{l}\text { Plano de projeto deve conter } \\
\text { definições específicas iniciais } \\
\text { para que o contrato entre } \\
\text { universidade e empresa seja } \\
\text { feito. Também deverá dar } \\
\text { liberdade para alterações ao } \\
\text { longo do projeto por se tratar de } \\
\text { um ambiente de pesquisa. }\end{array}$ & $\begin{array}{c}\text { Paradoxo: } \\
\text { Burocracia/Pesquisa }\end{array}$ \\
\hline $\begin{array}{l}\text { Definição do } \\
\text { escopo: }\end{array}$ & Gestão Ágil & $\begin{array}{l}\text { Os projetos necessitam atender } \\
\text { com flexibilidade as } \\
\text { imprevisibilidades do ambiente } \\
\text { de pesquisa e por isso a gestão } \\
\text { deverá englobar este aspecto. }\end{array}$ & $\begin{array}{l}\text { Tipo de projeto: } \\
\text { Pesquisa }\end{array}$ \\
\hline $\begin{array}{l}\text { Gestão dos } \\
\text { recursos: }\end{array}$ & $\begin{array}{c}\text { Abordagem híbrida que } \\
\text { respeite a natureza do } \\
\text { projeto }\end{array}$ & $\begin{array}{l}\text { Deve conter definições } \\
\text { específicas iniciais para que o } \\
\text { contrato seja assinado. } \\
\text { Também deverá dar liberdade } \\
\text { para alterações ao longo do } \\
\text { projeto por se tratar de um } \\
\text { ambiente de pesquisa. }\end{array}$ & $\begin{array}{c}\text { Paradoxo: } \\
\text { Burocracia/Pesquisa }\end{array}$ \\
\hline $\begin{array}{l}\text { Funções do } \\
\text { coordenador: }\end{array}$ & $\begin{array}{l}\text { Repensada pela instituição } \\
\text { (dependência de aspectos } \\
\text { estruturais/organizacionais) }\end{array}$ & $\begin{array}{l}\text { Não delimitação de um } \\
\text { coordenador dedicado e suas } \\
\text { funções diante da equipe. A } \\
\text { alocação de um gestor de } \\
\text { projeto profissional ainda } \\
\text { encontra barreiras dentro da } \\
\text { estrutura universitária típica. }\end{array}$ & $\begin{array}{l}\text { Equipe de projeto } \\
\text { está relacionada às } \\
\text { atividades além do } \\
\text { laboratório: aulas, } \\
\text { artigos. }\end{array}$ \\
\hline $\begin{array}{c}\text { Localização da } \\
\text { equipe de projeto: }\end{array}$ & Gestão Ágil & $\begin{array}{l}\text { Membros colocalizados, na qual } \\
\text { a auto-gestão seja realizada de } \\
\text { maneira positiva é fundamental } \\
\text { em um cenário onde alunos são } \\
\text { os principais desenvolvedores. } \\
\text { Essa estrutura ainda permite } \\
\text { troca de conhecimento tácito. }\end{array}$ & $\begin{array}{l}\text { Tipo de projeto: } \\
\text { pesquisa } \\
\text { universitária. } \\
\text { Membros com } \\
\text { similaridades de } \\
\text { competências. }\end{array}$ \\
\hline $\begin{array}{l}\text { Equipes de } \\
\text { projeto: }\end{array}$ & Gestão Ágil & $\begin{array}{c}\text { Equipes pequenas, } \\
\text { comunicação rápida e efetiva, } \\
\text { facilitam mudanças sucessivas } \\
\text { de escopo. }\end{array}$ & $\begin{array}{l}\text { Tipo de projeto: } \\
\text { Pesquisa. }\end{array}$ \\
\hline $\begin{array}{c}\text { Monitoramento da } \\
\text { evolução do } \\
\text { projeto: }\end{array}$ & Gestão Ágil & $\begin{array}{c}\text { Dificuldade de estimar a } \\
\text { hierarquia e as durações das } \\
\text { atividades. }\end{array}$ & $\begin{array}{l}\text { Tipo de projeto: } \\
\text { Pesquisa. }\end{array}$ \\
\hline $\begin{array}{l}\text { Acompanhamento } \\
\text { do projeto: }\end{array}$ & Gestão Ágil & $\begin{array}{c}\text { Dada a dificuldade relacionada } \\
\text { ao desenvolvimento de } \\
\text { conhecimento, deverá estar } \\
\text { relacionado a resultados } \\
\text { tangíveis. }\end{array}$ & $\begin{array}{c}\text { Dificuldade de } \\
\text { organizar atividades } \\
\text { de forma } \\
\text { hierárquica/prever } \\
\text { durações. }\end{array}$ \\
\hline $\begin{array}{l}\text { Participação do } \\
\text { Cliente: }\end{array}$ & $\begin{array}{c}\text { Repensada pela instituição } \\
\text { (dependência das relações } \\
\text { anteriormente construídas } \\
\text { e do perfil do cliente } \\
\text { envolvido); }\end{array}$ & $\begin{array}{l}\text { A universidade não depende de } \\
\text { projetos com empresas para } \\
\text { sobreviver; Equipe acadêmica } \\
\text { lida tradicionalmente com } \\
\text { relações horizontais de parceria } \\
\text { e colaboração. Participação do } \\
\text { cliente nos moldes da gestão } \\
\text { ágil demanda perfil específico } \\
\text { de cliente e/ou atribuição do } \\
\text { papel do dono do produto na } \\
\text { estrutura acadêmica. }\end{array}$ & $\begin{array}{l}\text { Horizontalidade das } \\
\text { relações típicas de } \\
\text { pesquisa, } \\
\text { verticalidade das } \\
\text { relações típicas } \\
\text { cliente-fornecedor } \\
\text { no ambiente } \\
\text { empresarial }\end{array}$ \\
\hline
\end{tabular}

Fonte: dos autores 
Por fim, apontam-se duas variáveis cujas características são muito particulares do contexto de pesquisa das parcerias universidades-empresa. A Função do Coordenador, algumas vezes não compreendidas pelos próprios membros da equipe, deverá ser alinhada dentro do laboratório, definindo o papel do gerente de projetos e suas respectivas responsabilidades. É importante citar o fato de que a equipe de projeto geralmente não está apenas envolvida com o laboratório - professores envolvidos com aulas e publicação de artigos; alunos envolvidos com as disciplinas, etc. - e que por isso, se faz ainda mais necessário o alinhamento de funções dentro do projeto. A segunda, Participação do Cliente, possui uma especificidade relacionada ao fato das universidades trabalharem com relações horizontais, de parceria e cooperação e dos laboratórios não dependerem financeiramente dos projetos com empresas. Seria importante avaliar, caso-a-caso, para definir a melhor estratégia de gestão desta relação. O Quadro 3 foi elaborado após análise do cenário de campo e mescla contribuições extraídas da literatura de GP com aspectos institucionais e estruturais das universidades. As variáveis, entretanto, necessitam ser estudadas também em outros projetos, com intuito de atingir uma proposta de abordagem que respeite as particularidades do ambiente de pesquisa, mas que torne a GP efetiva e benéfica para os laboratórios.

\section{CONCLUSÃO}

Este trabalho visou diagnosticar as contingências e particularidades de projetos de TI realizados por universidades em parceria com empresas a fim de fomentar abordagens de gestão mais adequadas. Os principais limitadores se devem a questões de confidencialidade, o número reduzido de projetos estudados e o viés de um laboratório em particular, e o fato de os dados refletirem apenas a perspectiva dos membros da universidade. Futuramente, o estudo poderia ser complementado com as percepções de empresas que realizam este tipo de projeto.

O estudo oferece uma análise inicial e uma reflexão pautada por dimensões identificadas na GP que podem auxiliar no aprimoramento dos projetos de pesquisa universidade-empresa. A pesquisa destaca ainda particularidades e contingências na área de projetos de pesquisa e faz uma reflexão sobre as possibilidades da GP aplicada a este contexto. Para as empresas, este trabalho traz informações sobre a natureza dos projetos no contexto universidade-empresa, atenta para possíveis situações a ser evitadas e aponta dificuldades enfrentadas pelas equipes em projetos reais. Conclui-se ainda que o trabalho é mais vantajoso quando considerado como parceria horizontal por ambas as partes.

Propõem-se como sugestão de estudos futuros, a extensão do diagnóstico de contingências e particularidades a outras áreas de pesquisa, a fim de analisar as abordagens de GP adequadas a outros contextos. Outra sugestão engloba a análise dos demais projetos de TI do contexto estudado ou mesmo intervenções guiadas por Pesquisa-Ação, com o propósito de realizar um estudo mais exaustivo das variáveis influentes na GP para derivação de soluções práticas.

\section{REFERÊNCIAS}

CODAS, M. Gerência de projetos - uma reflexão histórica. Adm. Empr., Rio de Janeiro, v. 27, n. 01, p.33-37, jan./mar. 1987.

EDER, S.; CONFORTO, E.; AMARAL, D.; SILVA, S. Diferenciando as abordagens tradicional e ágil de Gerenciamento de Projetos. Production., São Paulo , v. 25, n. 03, p. $482-$ 497, jul/set. 2015.

FERNANDEZ, D.; FERNANDEZ, J. Agile Project Management - agilism versus traditional 
approaches. Journal of Computer Information Systems, p. 10-17, winter. 2009.

HIGHSMITH, J. Gerenciamento Ágil de Projeto: Criando Produtos Inovadores. AltaBooks Editora, Tradução da 2a edição, 2012

HODA, R.; NOBLE, J.; MARSHALL, S. Agile Project Management, Christchurch , p. 218221, abr. 2008.

LOPES, L.; MAÑAS, A. Atrasos em projetos de TI causados por falhas na gestão dos stakeholders. 2012. 37 f. Dissertação - Pontifícia Universidade Católica, São Paulo, 2012.

MARQUES JUNIOR, L.; PLONSKI, G. Gestão de projetos em empresas no Brasil: abordagem "tamanho único"?. Gestão \& Produção, v.18, n.1, p.1-12, 2011.

PROJECT MANAGEMENT INSTITUTE. Certifications. Disponível em: $<$ http://www.pmi.org>. Acesso em: 06 nov. 2016.

SHENHAR, A.; DVIR, D. Reinventando Gerenciamento de Projetos. São Paulo: M.books do Brasil Editora Ltda., 2007.

SHI, Q. Rethinking the implementation of project management: A Value Adding Path Map approach. International Journal of Project Management., v. 29, p. 295-302, 2011.

SOFTEX - TECNOLOGIA DA INFORMAÇÃO BRASILEIRA. Projetos para o Setor. Disponível em: <http://www.softex.br/projetos-para-o-setor/>. Acesso em: 06 nov. 2016.

SPUNDAK, M. Mixed agile/traditional project management methodology - reality or illusion?. Procedia - Social and Behavioral Sciences., v. 119, p. 939-948, mar. 2014. 